\title{
Formal Verification of Tree Ensembles in Safety-Critical Applications
}

John Törnblom 



\title{
Formal Verification of Tree Ensembles in Safety-Critical Applications
}

\author{
John Törnblom
}

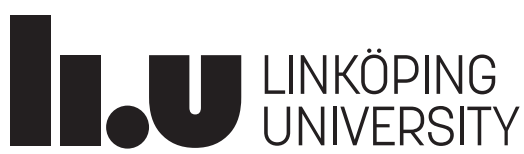

Linköping University

Department of Computer and Information Science Division for Software and Systems SE-581 83 Linköping, Sweden

Linköping 2020 
This is a Swedish Licentiate's Thesis

Swedish postgraduate education leads to a doctor's degree and/or a licentiate's degree. A doctor's degree comprises 240 ECTS credits (4 years of full-time studies).

A licentiate's degree comprises 120 ECTS credits.

Edition 1:1

(C) John Törnblom, 2020

ISBN 978-91-7929-748-0

ISSN 0280-7971

URL http://urn.kb.se/resolve?urn=urn:nbn:se:liu:diva-170862

Published articles have been reprinted with permission from the respective copyright holder.

Typeset using $\mathrm{X}_{\mathrm{H}} \mathrm{T}_{\mathrm{E}} \mathrm{X}$

Printed by LiU-Tryck, Linköping 2020 


\begin{abstract}
In the presence of data and computational resources, machine learning can be used to synthesize software automatically. For example, machines are now capable of learning complicated pattern recognition tasks and sophisticated decision policies, two key capabilities in autonomous cyber-physical systems. Unfortunately, humans find software synthesized by machine learning algorithms difficult to interpret, which currently limits their use in safety-critical applications such as medical diagnosis and avionic systems. In particular, successful deployments of safety-critical systems mandate the execution of rigorous verification activities, which often rely on human insights, e.g., to identify scenarios in which the system shall be tested.
\end{abstract}

A natural pathway towards a viable verification strategy for such systems is to leverage formal verification techniques, which, in the presence of a formal specification, can provide definitive guarantees with little human intervention. However, formal verification suffers from scalability issues with respect to system complexity. In this thesis, we investigate the limits of current formal verification techniques when applied to a class of machine learning models called tree ensembles, and identify model-specific characteristics that can be exploited to improve the performance of verification algorithms when applied specifically to tree ensembles.

To this end, we develop two formal verification techniques specifically for tree ensembles, one fast and conservative technique, and one exact but more computationally demanding. We then combine these two techniques into an abstraction-refinement approach, that we implement in a tool called VoTE (Verifier of Tree Ensembles).

Using a couple of case studies, we recognize that sets of inputs that lead to the same system behavior can be captured precisely as hyperrectangles, which enables tractable enumeration of input-output mappings when the input dimension is low. Tree ensembles with a high-dimensional input domain, however, seems generally difficult to verify. In some cases though, conservative approximations of input-output mappings can greatly improve performance. This is demonstrated in a digit recognition case study, where we assess the robustness of classifiers when confronted with additive noise. 



\section{Acknowledgments}

First, I would like to thank my academic supervisor Simin Nadjm-Tehrani, for challenging my ideas, for helping me to improve the accuracy and clarity of my communicative capabilities, and for guiding me through the academic landscape. Secondly, I would like to thank my industrial advisor Ingemar Söderquist, for giving me the opportunity to pursue a $\mathrm{PhD}$, and for facilitating my involvement in related research efforts conducted by industry.

I would also like to thank my colleges at Saab, for reminding me about the need for balance between research and practical applications, and the value of interdisciplinary collaborations. A special shout-out goes to Anders Eriksson, for reminding me about the pleasure of finding things out, and the joy of close collaboration with academia.

I also like to thank my colleges at RTSLab, for the valuable feedback they have provided me with during our interactions, and for sharing their own exciting discoveries in related fields. To my fellow $\mathrm{PhD}$ students, thank you for making the difficult and sometimes frustrating parts of education so pleasant. A special thank you goes to Héctor, for enriching our interactions with his pragmatic and positive attitude.

Finally, I thank the Knut and Alice Wallenberg Foundation for funding Sweden's largest individual research program in history, the Wallenberg AI, Autonomous Systems and Software Program (WASP).

John Törnblom

Linköping, Sweden

November 2020 



\section{Contents}

$\begin{array}{ll}\text { Abstract } & \text { iii }\end{array}$

Acknowledgments $\quad$ V

Contents vii

1 Introduction $\quad 1$

1.1 Motivation . . . . . . . . . . . . . . . . 1

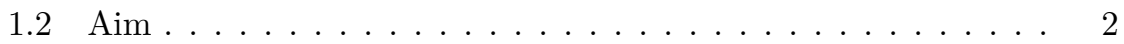

1.3 Thesis Outline ...................... 2

2 Background $\quad 3$

2.1 Formal Verification . . . . . . . . . . . . . . . . . 4

2.2 Machine Learning . . . . . . . . . . . . . . . . . 5

2.3 Studied Properties . . . . . . . . . . . . . . . 7

3 Research Overview 9

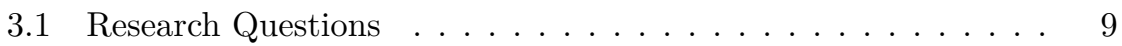

3.2 Contributions . . . . . . . . . . . . . . . . . 11

3.3 Related Works . . . . . . . . . . . . . . . . . . . . . . . . . . 13

3.4 Conclusions . . . . . . . . . . . . . . 16

3.5 Future Works . . . . . . . . . . . . . . . . . 17

$\begin{array}{lr}\text { Bibliography } & 19\end{array}$

$\begin{array}{ll}\text { Paper I } & 25\end{array}$

$\begin{array}{ll}\text { Paper II } & 45\end{array}$

$\begin{array}{lr}\text { Paper III } & 65\end{array}$ 



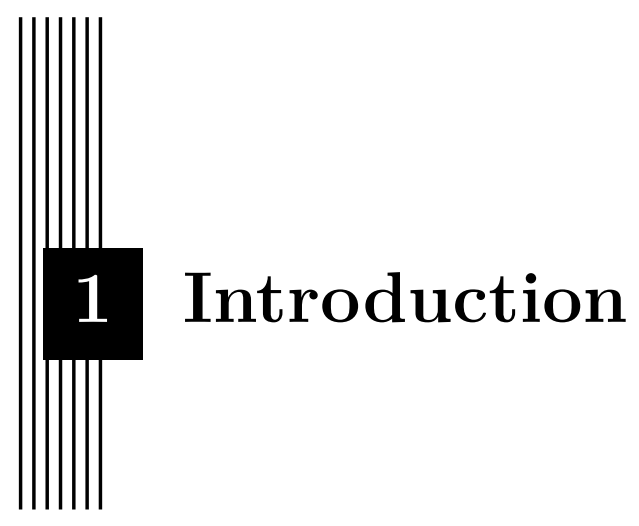

Recent advances in machine learning (ML) marks a new milestone towards artificial intelligence (AI). In particular, machines are now capable of learning complicated pattern recognition tasks, and sophisticated decision policies. Several of these advances have contributed to new types of software that are already well-established in commercial products and services, e.g., web search engines, spam filters, and voice user interfaces. These success stories are credited to, amongst other things, rapid improvements in computing hardware, and increased access to training data.

However, ML-based systems demonstrate faulty behavior from time to time, and preventing all of these faults from occurring has proved difficult. Fortunately, developers of commercialized ML-based systems have over time managed to reduce the number of occurring faults to a point that is acceptable for many applications. Furthermore, these systems are incrementally improved over time as more data becomes available. In safety-critical applications, however, such an incremental and somewhat optimistic approach is normally not viable since the negative impact caused by errors may have irreversible effects on human lives and the environment.

\subsection{Motivation}

To ensure safety, design organizations in industries such as medicine and transportation rely on well-established processes, methods, and tools (PM\&Ts) to ensure the absence of errors in their systems. Unfortunately, 
some of these PM\&Ts are incompatible with ML-based systems since machine learning models are notoriously difficult to interpret, hence rendering PM\&Ts that rely on human comprehension ineffective. For example, when design organizations develop test cases, they use human insights to identify equivalence classes, i.e., sets of system inputs that cause the same system behavior. Without such insights, software testing is either ineffective due to a lack of important test cases, or intractable due to an abundance of test cases that takes too long to execute.

\section{$1.2 \quad$ Aim}

A natural pathway towards viable verification strategies of ML-based systems for safety-critical applications is to leverage formal analyses, which unlike tractable testing strategies, can provide definitive guarantees. However, formal verification suffer from scalability issues with respect to system complexity. Consequently, the aim of this thesis is to understand shortcomings of existing formal techniques when applied to non-trivial ML-based systems, and to address these shortcomings by tailoring verification algorithms specifically for machine learning systems. In particular, this thesis address formal verification of a class of machine learning models known as tree ensembles, e.g., random forests and gradient boosting machines.

\subsection{Thesis Outline}

Chapter 2 presents background information on formal verification, machine learning in general, and tree ensembles in particular. Chapter 3 presents an overview of the research conducted prior to the writing of this thesis. In particular, the research overview includes questions that guided our research, a technical overview of the three publications included in this thesis (Papers I-III), and how these contributions address the research questions. We then relate these contributions to other's work, and end the chapter by mentioning future challenges this line of research still faces. The thesis ends with copies of the three papers detailing our contributions. 


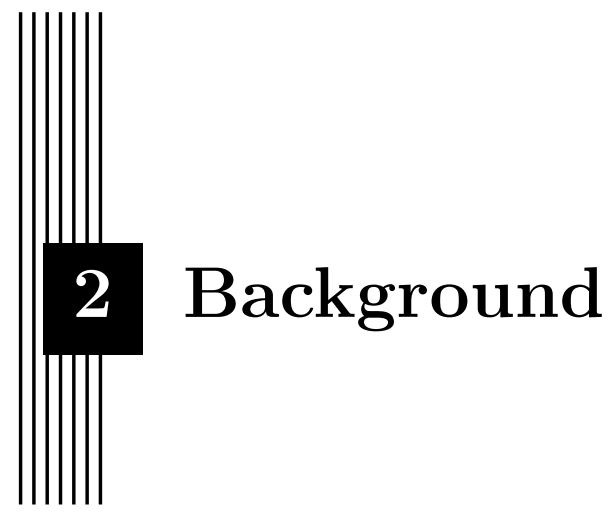

The ability of a system to meet its stakeholder's needs is often determined by the quality of the system specification, i.e., what the system shall do (or not do). The specification is normally derived from several different and potentially competing needs, and is foundational to verification activities. When verifying that a safety-critical system complies with its specification, extra care is given to statements that, when violated, may cause harm to humans or the environment. Here, we call these statements safety properties.

Systems can be further categorized based on our current understanding of them, both in terms of what the system shall do (requirements specification), and how the system shall do it (implementation). Here, we group systems into the following three categories; (1) well-understood systems, (2) well-specified systems, and (3) partially specified systems.

With well-understood systems, we know what the expected system behavior is in all meaningful circumstances, we know how to realize such systems, and we understand even its smallest building blocks. By using machine learning to synthesize system components, non-functional properties such as (lower) development costs and (higher) system resource utilization could potentially be improved upon compared to traditional engineering techniques. One interesting example that falls into this category is the application domain used in the work by Kraska et al. [14], where machine learning is used to synthesize efficient index structures, which can improve the runtime performance of, e.g., hash tables and databases. 
With well-specified systems, we know what the system shall do, or alternatively, what the system shall not do. However, defining exactly how these systems should operate in order to satisfy its specification is extremely difficult. To address this issue, machine learning can be used to explore the system design space, and eventually synthesize an implementation. For example, Silver et al. [24] present a learning algorithm that can synthesize autonomous agents capable of playing complex board games, e.g., Go, chess and shogi (a Japanese variant of chess), with empirical results suggesting super-human capabilities. The rules and goal of these games are easy to specify and understand, but discovering and implementing a super-human decision policy that achieves the goal without violating the rules is extremely difficult.

Finally, with partially specified systems, we know what the system shall do in a limited number of circumstances, and extrapolating to all meaningful circumstances is difficult. For example, it is difficult to specify what all airport runways should look like (or not look like), but we can specify them by labeled examples, albeit an incomplete set of examples.

In all of these categories, formal verification is applicable, but to a varying degree. Formal verification can be used to support the construction of assurance cases, and the more complete the specification is, the more compelling the assurance cases become. Now, the concept of safety is important from an engineering perspective, and is the main motivation behind this thesis. From an algorithmic standpoint, however, the fact that properties may originate from different stakeholder needs is of less importance, be it safety, security, or functional expectations.

\subsection{Formal Verification}

Formal verification is an activity that proves or disproves that a realized system complies with its given specification. The term formal stems from the fact that desirable system properties are expressed in a formal language, and that the system subject to verification is captured by a formal model. When both the implementation and specification is formalized in an unambiguous language, verification algorithms can perform mathematical analyses that leads to verification outcomes with definitive guarantees.

It is well known that formal verification algorithms can be extremely computationally demanding, and the needed resources are believed to grow exponentially with respect to the system's complexity. In spite of that, complex real-world systems have been successfully verified using formal techniques, often by decomposing the system into smaller pieces, and leveraging conservative approximation techniques that reduce the complexity even further. As emphasized by Beckert and Hähnle [1], however, formal verification is not a silver bullet, since both decomposition and approximations comes with a price. When a system is refined into smaller and independently verifiable 
components, the system specification often needs to be refined into auxiliary specifications by human domain experts, an activity that can be very time consuming, difficult, and thus a source of erroneous human assumptions. Furthermore, approximations can sometimes be too conservative, which can lead to inconclusive verification outcomes, i.e., the used verification algorithm is unable decide between "pass" and "fail".

In this thesis, we present an abstraction technique that turns out to be very effective (in the sense that verification outcomes are conclusive) when verifying a couple of generic properties of non-trivial tree ensembles. We only address the verification of these particular properties, namely plausibility of range and robustness against input perturbations (as defined in Section 2.3), and leave the development of more complete and domain-specific sets of properties with a fully compliant implementation to future works.

\subsection{Machine Learning}

As a machine learning practitioner, there are many different types of models and learning algorithms to choose from, and knowing which one to pick for a particular problem requires domain knowledge and experience. In fact, Wolpert and Macready [35] conclude that under certain settings, any two coevolutionary algorithms used to train a model have the same performance when averaged across all possible problems, a conclusion often refereed to as the no free lunch theorem. Consequently, machine learning practitioners often train several different types of models, and compare their predictive performances on a particular set of test samples. In this thesis, we address formal verification of a class of machine learning models known as tree ensembles, which use decision trees as their primary building block. Tree-based models have demonstrated great predictive performance on learning problems where the training data fits into main memory. They are currently a popular and successful choice on kaggle.com, an online community where machine learning practitioners compete against each other by training different models on publicly available datasets.

\section{Decision Trees}

A decision tree implements a prediction function $t: \mathbb{R}^{n} \rightarrow \mathbb{R}^{m}$ by partitioning its input space of $n$ dimensions into disjoint regions, and associates each region with an output value of $m$ dimensions, e.g., as illustrated by Figure 2.1. The tree structure is evaluated in a top-down manner, where decision functions associated with intermediate nodes determine which path to take towards the leaves, and ultimately which $m$-tuple to output.

In general, decision functions in decision trees may be non-linear and multivariate. Although researchers have demonstrated that decision trees with 

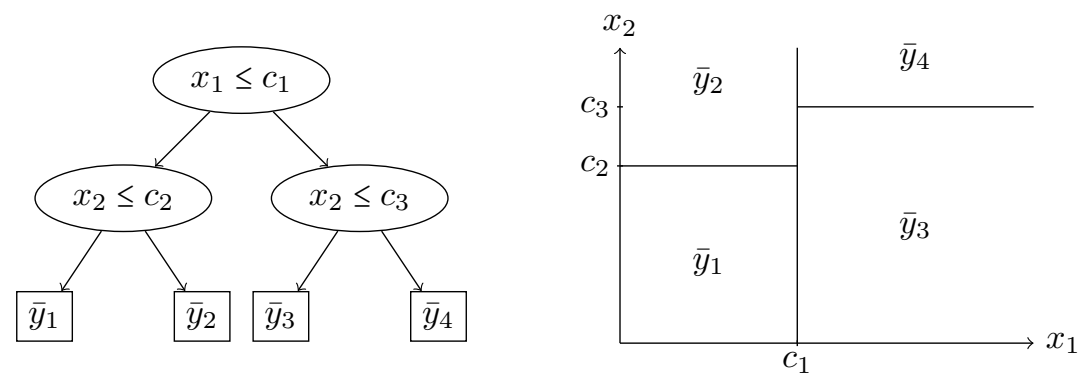

Figure 2.1: A decision tree (to the left) partition its input space into disjoint regions (to the right), and associates each region with an output value.

non-linear [12] and multivariate [33] decision functions can be useful, state-ofthe-art implementations of tree-based machine learning models normally only contain univariate and linear decision functions, e.g., the popular machine learning library named scikit-learn [18].

\section{Tree Ensembles}

Decision trees are known to suffer from a phenomenon called overfitting, i.e., the model becomes too specialized towards training data, and the prediction function generalizes poorly when confronted by previously unseen inputs. To counteract overfitting of decision trees, several types of tree ensembles have been proposed, e.g., random forests [2] and gradient boosting machines [10]. The different types of tree ensembles are normally distinguished by their learning algorithms, while their prediction functions have similar structure. Specifically, a tree ensemble implements a prediction function $f: \mathbb{R}^{n} \rightarrow \mathbb{R}^{m}$ as the sum of predictions from $B$ different decision trees, post-processed by a function $p$, i.e., $f(\bar{x})=p\left(\sum_{b=1}^{B} t_{b}(\bar{x})\right)$, where $t_{b}$ is the $b$-th tree. Table 2.1 defines post-processing functions used by common types of tree ensembles.

Table 2.1: Examples of post-processing functions.

\begin{tabular}{ll}
\hline Name & Definition \\
\hline Divisor & $p_{d}\left(y_{1}, \ldots, y_{m}\right)=\frac{\left(y_{1}, \ldots, y_{m}\right)}{B}$ \\
Softmax & $p_{s}\left(y_{1}, \ldots, y_{m}\right)=\frac{\left(e^{y_{1}}, \ldots, e^{y_{m}}\right)}{\sum_{i=1}^{m} e^{y_{i}}}$ \\
\hline
\end{tabular}

The divisor appears in the prediction function of random forests, while the softmax function often appears in gradient boosting machines trained on classification problems. 


\section{Classification}

Decision trees and tree ensembles as defined above output real-valued $m$ tuples, in which case they are refereed to as regressors by the machine learning community. By training a regressor to predict probabilities, they can be used as classifiers. Let $f(\bar{x})=\left(y_{1}, \ldots, y_{m}\right)$ be a function trained to predict the probability $y_{i}$ associated with a class $i$ within disjoint regions in the input space, where $m$ is the number of classes. A classifier $f_{c}: \mathbb{R}^{n} \rightarrow\{1, \ldots, m\}$ is then defined as

$$
f_{c}(\bar{x})=\underset{i \in\{1, \ldots, m\}}{\operatorname{argmax}} y_{i} .
$$

\subsection{Studied Properties}

In this thesis, we focus on two generic system properties commonly used by related works; plausibility of range, and robustness against input perturbations.

\section{Plausibility of Range}

Let $f: \mathbb{R}^{n} \rightarrow \mathbb{R}^{m}$ be a function subject to verification. The function has the desired plausibility of range when its output values are within a stated boundary, i.e.,

$$
\begin{array}{r}
\forall \bar{x} \in \mathbb{R}^{n}, \forall i \in\{1, \ldots, m\}, \\
f(\bar{x})=\left(y_{1}, \ldots, y_{m}\right), \\
\alpha_{i} \leq y_{i} \leq \beta_{i},
\end{array}
$$

where $\alpha_{i}, \beta_{i} \in \mathbb{R}$. In classification problems, the used function predicts probabilities, and thus $\alpha_{i}=0$ and $\beta_{i}=1$.

\section{Robustness against Input Perturbations}

Bruneau et al. [3] describe robustness as the ability of a system to withstand a given level of stress without suffering degradation or loss of functionality. In the context of machine learning, such a description includes a classifier's ability to maintain decisiveness in its predictions, despite noisy or adversarial input. Formally, such a relationship between inputs and outputs may be defined as follows.

Let $f_{c}$ be a classifier subject to verification, $X \subset \mathbb{R}^{n}$ a set of input samples, $\epsilon \in \mathbb{R}_{\geq 0}$ a robustness margin, and $\Delta=\{\delta \in \mathbb{R}:-\epsilon<\delta<\epsilon\}$ perturbations. We denote by $\bar{\delta}$ a tuple of perturbations, i.e., an $n$-tuple of elements drawn from $\Delta$. The classifier is robust against perturbations with respect to $X$ and $\Delta$ iff

$$
\begin{gathered}
\forall \bar{x} \in X, \forall \bar{\delta} \in \Delta^{n}, \\
f_{c}(\bar{x})=f_{c}(\bar{x}+\bar{\delta}) .
\end{gathered}
$$


In many applications, the concept of robustness may also include additional types of input perturbations, e.g., axial rotations in computer vision. Furthermore, this property relies on the set of input samples $X$, which is normally only partially specified. 


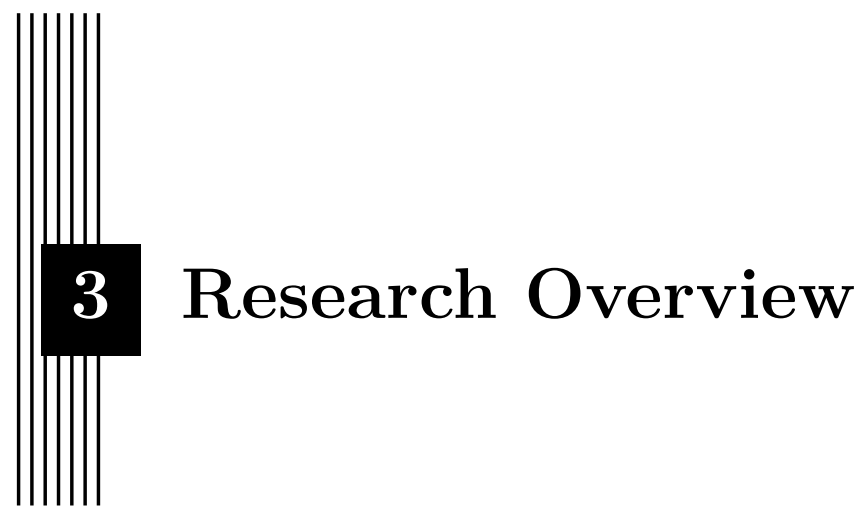

This chapter provides on overview of the research presented in this thesis. In particular, Section 3.1 defines research questions that guided our work, Section 3.2 provides an overview of the three papers that make up the scientific content of this thesis, and Section 3.3 provides a summary of related works. We then conclude the thesis in Section 3.4, and Section 3.5 mentions some of the future works and challenges this line of research still faces.

\subsection{Research Questions}

As explained in Section 1.2, the aim of this thesis is to provide an understanding of limitations with existing formal verification techniques when applied to non-trivial tree ensembles, and to explore possible algorithmic opportunities by tailoring verification algorithms specifically for tree ensembles. This section elaborates on that aim by defining two research questions: one related to the characteristics of tree ensembles, and another related to scalability.

As discussed in Section 2.1, the computational resources needed to solve verification problems are believed to grow exponentially with respect to system complexity. Consequently, at some particular complexity barrier, the computational resources needed grow so fast that problems become intractable, as illustrated by Figure 3.1.

Given the inevitable scalability barrier generally associated with formal verification, the need for more efficient verification algorithms is eminent. One way to push the scalability barrier forward is to design heuristic algorithms 


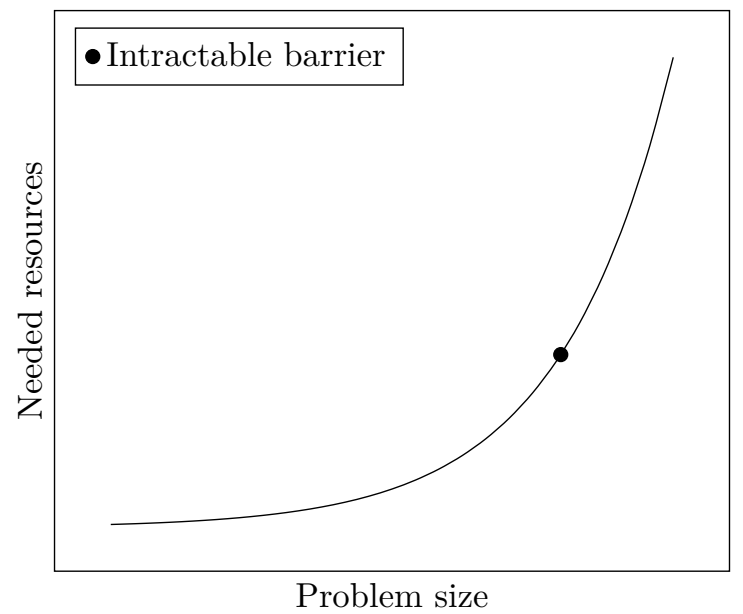

Figure 3.1: Verification problems larger than a particular barrier are intractable due to a lack of computational resources.

that trade generalisation for efficiency, i.e., verification algorithms designed specifically for a particular model. This leads us to our first research question addressed by this thesis:

\section{RQ1: are there characteristics of tree ensembles that can be ex- ploited by formal verification algorithms?}

Decades of research in computing hardware and algorithmic heuristics have managed to push this barrier forward, rendering formal verification applicable to several practical problems, e.g., formal verification of hardware circuitry, and software systems defined in languages such as Ada SPARK. However, little is known about this barrier when formal verification is applied to tree ensembles, e.g., how many trees, tree depth, and number of input and output variables can be used before the complexity barrier is encountered. This leads us to our second research question addressed by this thesis:

\section{RQ2: is it possible to formally verify non-trivial tree ensembles with reasonable amounts of computing resources?}

In this thesis, we consider a couple of days of exclusive access to a modern workstation as reasonable amount of computing resources, and we address case studies with tree ensembles that are too complex for exhaustive testing to be applicable. With a tree ensemble of 10 trees, each with a depth of 10 , the rule of product yields $2^{100}$ ways of combining outputs from different trees, which is clearly an intractable number of combinations to test. Although highly dependent on the type of tree ensemble, application, and context, the 
number of trees in a tree ensembles is typically in the range $10-1,000$, and the tree depth is often in the range $2-20$.

\subsection{Contributions}

This thesis is based upon three publications, as illustrated by Figure 3.2. Paper I was presented at the 6th International Workshop on Formal Techniques for Safety-Critical Systems (FTSCS) in November 2018, and later published in Communications in Computer and Information Science (CCIS) volume 1008, contributing with formal verification techniques designed specifically for random forests. Based on that work, we were later invited to submit an extended version of that paper to a special issue of the Science of Computer Programming journal, where we optimized and generalized principles from Paper I. Finally, Paper III was presented at the 2nd International Workshop on Artificial Intelligence Safety Engineering (WAISE), held in conjunction with the SAFECOMP conference in September 2019, and later published in Lecture Notes in Computer Science (LNCS) volume 11699. In that work, we combined techniques from Paper II to device an abstraction-refinement approach that yields speed improvements of several orders of magnitude.

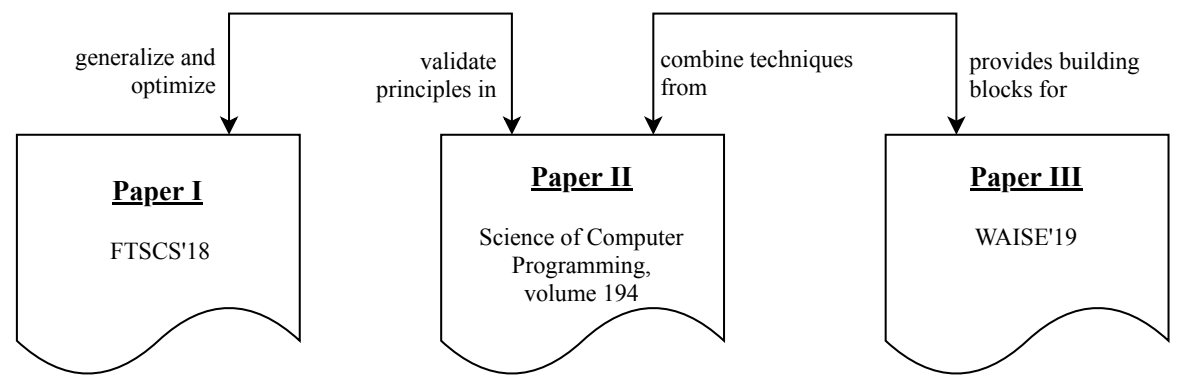

Figure 3.2: Illustration of papers in this thesis, where they were initially presented, and how the papers relate to each other.

The remainder of this section provides an overview of technical achievements of each individual paper. 


\section{Paper I: Formal Verification of Random Forests in Safety-Critical} Applications by John Törnblom and Simin Nadjm-Tehrani, presented at the 6th International Workshop on Formal Techniques for Safety-Critical Systems (FTSCS), November 2018, published in Communications in Computer and Information Science (CCIS), volume 1008, Springer, February 2019.

In this paper, we present two formal verification techniques developed specifically for random forests; one fast and conservative technique that computes input-output approximations of random forests, and one exact but more computationally demanding technique that computes equivalence classes, i.e., sets of input values that all yield exactly the same output value.

We implement the verification techniques in a tool named VoRF (Verifier of Random Forests), and verify requirements placed on digit recognition classifiers and collision detection classifiers. Specifically, we use VoRF to verify that probabilities predicted in classifiers are always in the range $[0,1]$ (the so-called range plausibility property), and that test accuracies are unaffected when test inputs are augmented by additive noise (a robustness property). As it turns out, all classifiers verified in the two case studies always compute probabilities in the range $[0,1]$, but all classifiers are sensitive to minor additive noise. In some experiments from the digit recognition case study, changing a single pixel value by $0.5 \%$ is enough to change the classification outcome.

We also evaluate VoRF in terms of runtime performance, and conclude that the conservative technique is fast, but is often inconclusive. In such cases, we used the exact but more computationally demanding technique, which turns out to be practical for random forests trained on low-dimensional data with up to 25 decision trees, each with a tree depth of 20 . To the best of our knowledge, this is the first published work that demonstrates that formal analysis of tree-based machine learning models can be computationally practical when applied to non-trivial verification problems.

\section{Paper II: Formal Verification of Input-Output Mappings of Tree}

Ensembles by John Törnblom and Simin Nadjm-Tehrani, published in Science of Computer Programming, a special issue on Formal Techniques for Safety-Critical Systems, Elsevier, 2020.

This paper is an extended and significantly improved version of Paper I, where we present generalizations of the two previously published techniques to include an additional tree-based machine learning model, namely, gradient boosting machines. In particular, we show that both random forests and gradient boosting machines can be captured by a single model of additive trees, post-processed by a parameterized function $p$. We further prove that input-output approximations computed by the non-exact technique are in- 
deed conservative, as long as $p$ is monotonic. In the case of random forests, $p$ is a simple constant division with the number of trees, while the addition of trees in gradient boosting machines trained on classification problems are post-processed by the softmax function, which is known to be monotonic.

Based on conclusions from Paper I, this paper also suggests an algorithmic change that improves the runtime performance of the exact verification technique. More specifically, we observed that tree ensembles normally contain infeasible path combinations which may be discarded from analysis. With the algorithmic change proposed in Paper II in place, we are able to detect these infeasible paths earlier in the analysis than before, which significantly reduces the elapsed time taken during verification, in some cases up to 10 times faster.

\section{Paper III: An Abstraction-Refinement Approach to Formal Verification of Tree Ensembles by John Törnblom and Simin} Nadjm-Tehrani, presented at the 2nd International Workshop on Artificial Intelligence Safety Engineering (WAISE), September 2019, published in Lecture Notes in Computer Science (LNCS), volume 11699, Springer, 2019.

In this paper, we combine the two generalized techniques from Paper II into an abstraction-refinement approach to address combinatorial explosions observed while verifying the high-dimensional digit recognition case study in Paper II. We tailored the approach specifically to assess robustness against additive noise, and implemented it in the toolsuite VoTE (Verifier of Tree Ensembles). As illustrated in Figure 3.3, the approach is realized in a pipeline architecture with alternating abstraction and refinery elements, with the significant additions made to the VoTE implementation as part of this work highlighted in bold.

As mentioned earlier in this chapter, our previous works outputs equivalence classes $\left(X_{i}, \bar{y}_{i}\right)$, such that $\forall \bar{x} \in X_{i}, f(\bar{x})=\bar{y}_{i}$, where $f$ is the prediction function of a tree ensemble. With the algorithmic changes presented in this paper in place, the outputs produced by VoTE are conservative approximations of input-output mappings $\left(X_{i}, Y_{i}\right)$, such that $\forall \bar{x} \in X_{i}, f(\bar{x}) \in Y_{i}$.

It turns out that analyzing conservative approximations of input-output mappings is significantly more efficient when verifying the robustness aspects of our case studies compared to earlier works that analyze equivalence classes. In particular, the elapsed time taken during verification was reduced by several orders of magnitude, now scaling to tree ensembles with up to 50 trees with depth 10, trained on high-dimensional data.

\subsection{Related Works}

In this section, we summarize related works that address the verification of machine learning models using various formal techniques. The section is struc- 


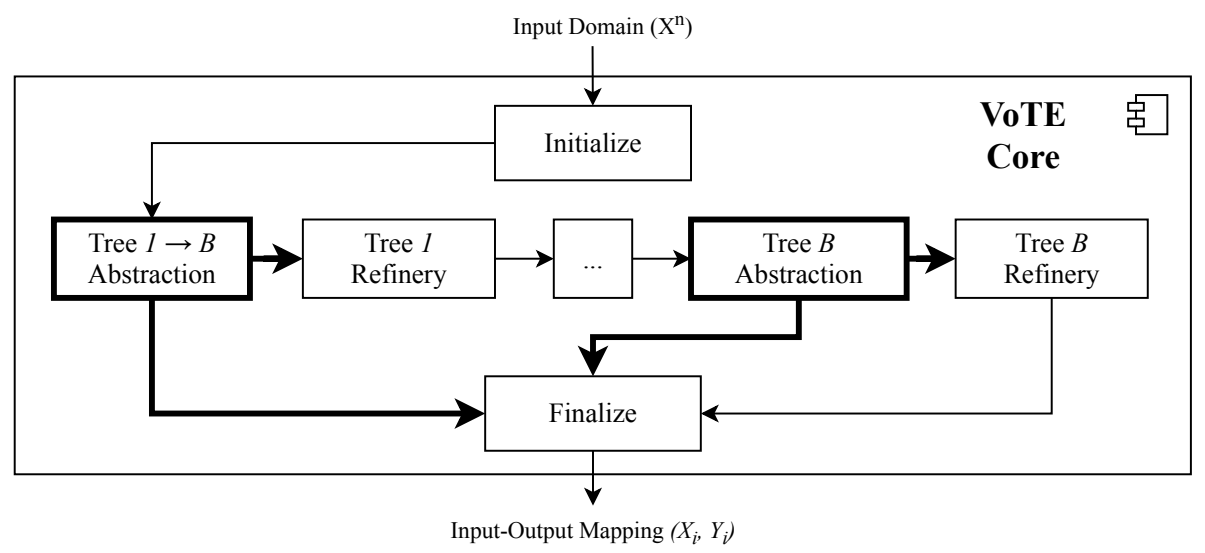

Figure 3.3: The abstraction-refinement approach is realized in VoTE using a pipeline architecture with alternating abstraction and refinery elements. Significant additions we made to the VoTE implementation as part of this work are highlighted in bold.

tured according to the machine learning model subject to verification, then ordered chronologically according to year of publication.

\section{Neural Networks}

Pulina and Tacchella [19] present a tool called NeVer which, to the best of our knowledge, is the earliest published work that uses formal techniques to verify a machine learning model. Specifically, Pulina and Tacchella present an abstraction-refinement technique that approximates the non-linear logistic function in neural networks by a set of intervals, which are refined into smaller pieces when the outcome of the verification result is inconclusive. They demonstrate their approach in a case study where a robotic arm is controlled by a neural network. Pulina and Tacchella then continue to improve their abstraction-refinement approach [21], and also explore the limits of SMT solvers by encoding the verification problem as one large SMT formula [20]. They conclude that formal verification of non-trivial neural networks is still an open challenge. In our works, we address similar properties as Pulina and Tacchella, i.e., plausibility of range and robustness against input perturbations.

Fast-forward to the year 2017, when deep learning appears on the Gartner hype cycle for the first time [32], an annual report produced by the research and advisory firm Gartner to explain general phenomena of interest in new technologies. State-of-the-art neural networks are now even larger in terms of size, and concerns regarding their implications on safety in applications such as autonomous vehicles accelerate the pursuit for viable verification strategies. 
Around this time, the progress made in deep learning yielded significantly larger neural networks than before, but often containing simpler activation functions, e.g., the ReLU activation function which is piece-wise linear. Since then, this piece-wise linear property of many modern deep learning models have been exploited by several researchers. In particular, researchers have explored SAT- and SMT-based techniques $[13,5]$, various linear programming schemes $[8,11,28]$, abstract interpretation[16, 25, 26], and a mixture of multiple techniques $[7,34,17,27]$. In this thesis, we verify similar properties in similar case studies as these works, but for tree ensembles.

\section{Tree Ensembles}

Chen et al. [4] verify the robustness of tree ensembles by expressing the robustness verification problem as a max-clique graph problem, and present an approach that leads to a polynomial time algorithm when the input dimension of tree ensembles is low. These results confirm our earlier observations from Paper II, i.e., that formal verification of tree ensembles with few input variables can be practical, even for non-trivial models.

Einziger et al. [9] present a tool named VeriGB capable of verifying the robustness of gradient boosting machines. They encode the verification problem as an SMT formula, and use an off-the-shelf SMT solver to compute the verification outcome. They design the SMT formula to facilitate parallel analyses, which they leverage in three case studies executed on a machine with 36 CPU cores. Even though they experience timeouts on particularly difficult verification problems, their approach is able to quantify the robustness by treating verification problems that time out as negative outcomes. Similarly, Sato et al. [23] leverage an SMT solver, but address the plausibility of range property. When the SMT solver discovers an illegal output value, they extract the corresponding input, and construct a preprocessing filter that can prevent the violation from occuring when deployed into a production system. Current work by Devos et al. [6] also leverage an SMT solver, but aims for any tree ensemble verification problem that can be expressed as an SMT formula.

Compared to these works, we leverage conservative approximations in intermediate computations, which often reduce the elapsed time taken during verification, at the expense of precision. In Paper III, we present an abstraction-refinement approach that we implement in the tool VoTE (Verifier of Tree Ensembles). We compare empirical results from Paper II (which also uses VoTE, but without the abstraction-refinement approach), and conclude that conservative approximations decreased the elapsed time taken during verification by several orders of magnitude.

Ranzato and Zanella [22] extend on our work by formulating the abstraction-refinement approach from Paper III in an abstract interpretation framework, and implement the approach in a tool called Silva. Compared to VoTE, Silva is designed to support multiple abstract domains, and uses a 
best-first tree exploration algorithm, whereas VoTE uses a depth-first algorithm. Ranzato and Zanella conclude that Silva outperforms VoTE in terms of elapsed time during verification. However, we have identified several shortcomings in their experimental setup, which could have affected the validity of their conclusions. These concerns were recently confirmed by Lundström [15], In particular, Lundström shows that VoTE uses significantly less memory than Silva, and that VoTE is marginally better than Silva in terms in elapsed time during verification when experiments are performed in a consistent (fair) setting. In our current work (that is not part of this thesis), we leverage the small memory foot-print of VoTE to parallelize the robustness verification across multiple CPU cores, an approach which we believe may not be practical with a best-first algorithm due to memory limitations.

\subsection{Conclusions}

As described in Section 3.1, this thesis addresses two research question: one (RQ1) relating to characteristics of tree ensembles that can be exploited by formal verification algorithms, and another (RQ2) relating to the scalability of formal verification algorithms when are applied to non-trivial tree ensembles. In the following sections, we discuss these two questions individually.

\section{Characteristics of Tree Ensembles}

The size and complexity of tree ensembles is primarily determined by the number of trees, and the depth of each tree. These model parameters also determine the number of path combinations amongst trees, and thus the theoretical upper limit on the number of equivalence classes in a tree ensemble. In Papers I and II, we conclude that the actual number of equivalence classes in tree ensembles with a small number of input variables is significantly lower than the number of path combinations, since several combinations are infeasible. This conclusion was later confirmed by Chen et al. [4], where they prove that the robustness of gradient boosting machines against additive noise is verifiable in polynomial time, as long as the input dimension is low.

Furthermore, we recognize that state-of-the-art machine learning libraries synthesize trees with univariate and linear decision functions. Consequently, sets of inputs may be captured precisely as hyperrectangles, which facilitates efficient reasoning of input-output mappings.

\section{Scalability}

In Papers I and II, we demonstrate via a collision detection case study that non-trivial tree ensembles can be verified using a moderate workstation in less than a day, as long as the input dimension is low. This is made possible since tree ensembles with a small number of input dimensions contain 
many infeasible path combinations, which can be exploited by a verification algorithm to efficiently compute and enumerate equivalence classes. As the input dimension grows, however, the number of infeasible path combinations is reduced. Tree ensembles with a high-dimensional input domain seem to be generally difficult to verify. In some cases though, conservative approximations can greatly improve performance. In Paper III, we demonstrate via a digit recognition case study that its possible to verify robustness of additive noise of tree ensembles, even when the input dimension is large.

\subsection{Future Works}

Modern computers are equipped with several CPU cores, most of which are unused when executing the current implementation of VoTE. When verifying robustness against input perturbations, each sample from a test set is analyzed in sequence. This sequence is trivially parallelizable across multiple CPU cores, and a near-linear speedup with respect to number of CPU cores is to be expected, assuming sufficient memory is available.

The abstraction-refinement approach currently implemented in VoTE refines conservative approximations using information from trees that appear in a fixed and predetermined order. By reordering trees dynamically before each refinement step based on how much each tree contributes to the widening of the output approximation, the number of refinement steps could potentially be reduced. Whether the dynamic reordering adds more overhead than what is gained from fewer refinement steps remains to be seen. We also plan to investigate trade-offs between the depth-first tree exploration algorithm implemented in VoTE, and the best-first tree exploration algorithm implemented in Silva, when executed concurrently on a many-core system.

Tools based on formal verification methods, in particular those that leverage conservative approximations, have demonstrated promising results in terms of run-time performance in several ML-based applications. However, formal verification assumes the presence of a formal specification, which is still incomplete in many applications of machine learning. In order to leverage formal verification in these applications, we must learn how to specify what we expect from them. Are these systems only partially specified due to insufficient engineering work, or are there fundamental issues at play that need further research? These are open questions to be studied in the future. 



\section{Bibliography}

[1] Bernhard Beckert and Reiner Hähnle. "Reasoning and verification: State of the art and current trends." In: IEEE Intelligent Systems 29.1 (2014), pp. 20-29.

[2] Leo Breiman. "Random forests." In: Machine learning 45.1 (2001), pp. 532. DOI: $10.1023 / \mathrm{A}: 1010933404324$.

[3] Michel Bruneau, Stephanie E Chang, Ronald T Eguchi, George C Lee, Thomas D O'Rourke, Andrei M Reinhorn, Masanobu Shinozuka, Kathleen Tierney, William A Wallace, and Detlof Von Winterfeldt. "A framework to quantitatively assess and enhance the seismic resilience of communities." In: Earthquake spectra 19.4 (2003), pp. 733-752.

[4] Hongge Chen, Huan Zhang, Si Si, Yang Li, Duane Boning, and Cho-Jui Hsieh. "Robustness verification of tree-based models." In: Advances in Neural Information Processing Systems (NIPS). 2019, pp. 12317-12328.

[5] Chih-Hong Cheng, Georg Nührenberg, Chung-Hao Huang, and Harald Ruess. "Verification of Binarized Neural Networks via Inter-neuron Factoring." In: Verified Software. Theories, Tools, and Experiments (VSTTE). Ed. by Ruzica Piskac and Philipp Rümmer. Springer International Publishing, 2018, pp. 279-290. ISBN: 978-3-030-03592-1.

[6] Laurens Devos, Wannes Meert, and Jesse Davis. "Additive Tree Ensembles: Reasoning About Potential Instances." In: arXiv preprint arXiv:2001.11905 (2020). 
[7] Souradeep Dutta, Susmit Jha, Sriram Sankaranarayanan, and Ashish Tiwari. "Output Range Analysis for Deep Feedforward Neural Networks." In: NASA Formal Methods (NFM). Ed. by Aaron Dutle, César Muñoz, and Anthony Narkawicz. Springer International Publishing, 2018, pp. 121-138. ISBN: 978-3-319-77935-5.

[8] Ruediger Ehlers. "Formal verification of piece-wise linear feed-forward neural networks." In: International Symposium on Automated Technology for Verification and Analysis (ATVA). Springer International Publishing, 2017, pp. 269-286. DOI: 10.1007/978-3-319-68167-2\_19.

[9] Gil Einziger, Maayan Goldstein, Yaniv Sa'ar, and Itai Segall. "Verifying Robustness of Gradient Boosted Models." In: Proceedings of the ThirtyThird AAAI Conference on Artificial Intelligence. AAAI Press, 2019, pp. 2446-2453.

[10] Jerome H Friedman. "Greedy function approximation: a gradient boosting machine." In: Annals of statistics (2001), pp. 1189-1232.

[11] Xiaowei Huang, Marta Kwiatkowska, Sen Wang, and Min Wu. "Safety Verification of Deep Neural Networks." In: Computer Aided Verification $(C A V)$. Ed. by Rupak Majumdar and Viktor Kunčak. Springer International Publishing, 2017, pp. 3-29. ISBN: 978-3-319-63387-9.

[12] Ozan Irsoy, Olcay Taner Yildız, and Ethem Alpaydın. "Soft Decision Trees." In: Proceedings of the 21st International Conference on Pattern Recognition (ICPR). IEEE, 2012, pp. 1819-1822.

[13] Guy Katz, Clark Barrett, David L Dill, Kyle Julian, and Mykel J Kochenderfer. "Reluplex: An efficient SMT solver for verifying deep neural networks." In: International Conference on Computer Aided Verification (CAV). Springer International Publishing, 2017, pp. 97-117. DOI: 10.1007/978-3-319-63387-9\_5.

[14] Tim Kraska, Alex Beutel, Ed H Chi, Jeffrey Dean, and Neoklis Polyzotis. "The case for learned index structures." In: Proceedings of the 2018 International Conference on Management of Data. 2018, pp. 489-504.

[15] Linnea Lundström. "Formally Verifying the Robustness of Machine Learning Models: A Comparative Study." In: DiVA publication diva2:1111111 (2020).

[16] Matthew Mirman, Timon Gehr, and Martin Vechev. "Differentiable Abstract Interpretation for Provably Robust Neural Networks." In: Proceedings of the 35th International Conference on Machine Learning (ICML). 2018, pp. 3578-3586.

[17] Nina Narodytska, Shiva Kasiviswanathan, Leonid Ryzhyk, Mooly Sagiv, and Toby Walsh. "Verifying properties of binarized deep neural networks." In: Thirty-Second AAAI Conference on Artificial Intelligence. 2018, pp. 6615-6624. 
[18] Fabian Pedregosa, Gaël Varoquaux, Alexandre Gramfort, Vincent Michel, Bertrand Thirion, Olivier Grisel, Mathieu Blondel, Peter Prettenhofer, Ron Weiss, Vincent Dubourg, et al. "Scikit-learn: Machine learning in Python." In: Journal of machine learning research 12 .Oct (2011), pp. 2825-2830.

[19] Luca Pulina and Armando Tacchella. "An Abstraction-Refinement Approach to Verification of Artificial Neural Networks." In: Computer Aided Verification. Ed. by Tayssir Touili, Byron Cook, and Paul Jackson. Berlin, Heidelberg: Springer Berlin Heidelberg, 2010, pp. 243-257. ISBN: 978-3-642-14295-6.

[20] Luca Pulina and Armando Tacchella. "Challenging SMT solvers to verify neural networks." In: AI Communications 25.2 (2012), pp. 117-135. DOI: $10.3233 /$ AIC-2012-0525.

[21] Luca Pulina and Armando Tacchella. "NeVer: A Tool for Artificial Neural Networks Verification." In: Annals of Mathematics and Artificial Intelligence 62.3-4 (2011), pp. 403-425.

[22] Francesco Ranzato and Marco Zanella. "Abstract Interpretation of Decision Tree Ensemble Classifiers." In: Proceedings of the Thirty-Fourth AAAI Conference on Artificial Intelligence. AAAI Press, 2020, pp. 54785486 .

[23] Naoto Sato, Hironobu Kuruma, Yuichiroh Nakagawa, and Hideto Ogawa. "Formal Verification of a Decision-Tree Ensemble Model and Detection of Its Violation Ranges." In: IEICE Transactions on Information and Systems 103.2 (2020), pp. 363-378.

[24] David Silver, Thomas Hubert, Julian Schrittwieser, Ioannis Antonoglou, Matthew Lai, Arthur Guez, Marc Lanctot, Laurent Sifre, Dharshan Kumaran, Thore Graepel, et al. "A general reinforcement learning algorithm that masters chess, shogi, and Go through self-play." In: Science 362.6419 (2018), pp. 1140-1144.

[25] Gagandeep Singh, Timon Gehr, Matthew Mirman, Markus Püschel, and Martin Vechev. "Fast and effective robustness certification." In: Advances in Neural Information Processing Systems. 2018, pp. 1080210813.

[26] Gagandeep Singh, Timon Gehr, Markus Püschel, and Martin Vechev. "An abstract domain for certifying neural networks." In: Proceedings of the ACM on Programming Languages 3.POPL (2019), pp. 1-30.

[27] Gagandeep Singh, Timon Gehr, Markus Püschel, and Martin Vechev. "Boosting Robustness Certification of Neural Networks." In: International Conference on Learning Representations (ICLR). 2019. 
[28] Vincent Tjeng, Kai Y. Xiao, and Russ Tedrake. "Evaluating Robustness of Neural Networks with Mixed Integer Programming." In: International Conference on Learning Representations (ICLR). 2019.

[29] John Törnblom and Simin Nadjm-Tehrani. "An Abstraction-Refinement Approach to Formal Verification of Tree Ensembles." In: Computer Safety, Reliability, and Security. Ed. by Alexander Romanovsky, Elena Troubitsyna, Ilir Gashi, Erwin Schoitsch, and Friedemann Bitsch. Cham: Springer International Publishing, 2019, pp. 301-313. ISBN: 9783-030-26250-1.

[30] John Törnblom and Simin Nadjm-Tehrani. "Formal verification of input-output mappings of tree ensembles." In: Science of Computer Programming 194 (2020).

[31] John Törnblom and Simin Nadjm-Tehrani. "Formal Verification of Random Forests in Safety-Critical Applications." In: Formal Techniques for Safety-Critical Systems. Ed. by Cyrille Artho and Peter Csaba Ölveczky. Cham: Springer International Publishing, 2019, pp. 55-71. ISBN: 978-3030-12988-0.

[32] Mike Walker. Hype Cycle for Emerging Technologies. Tech. rep. G00314560. 56 Top Gallant Road, Stamford, CT 06902-7700, USA: Gartner, Inc, 2017.

[33] Fei Wang, Quan Wang, Feiping Nie, Weizhong Yu, and Rong Wang. "Efficient tree classifiers for large scale datasets." In: Neurocomputing 284 (2018).

[34] Shiqi Wang, Kexin Pei, Justin Whitehouse, Junfeng Yang, and Suman Jana. "Efficient formal safety analysis of neural networks." In: Advances in Neural Information Processing Systems (NIPS). 2018, pp. 6367-6377.

[35] D. H. Wolpert and W. G. Macready. "Coevolutionary free lunches." In: IEEE Transactions on Evolutionary Computation 9.6 (2005), pp. 721735 . 


\section{Papers}

The papers associated with this thesis have been removed for copyright reasons. For more details about these see:

http://urn.kb.se/resolve?urn=urn:nbn:se:liu:diva-170862 


\section{Licentiate Theses}

\section{Linköpings Studies in Science and Technology Faculty of Arts and Sciences}

No 17

No 28

No 29

No 48

No 52

No 60

No 71

No 72

No 73

No 74

No 104

No 108

No 111

No 113

No 118

No 126

No 127

No 139

No 140

No 146

No 150

No 165

No 166

No 174

No 177

No 181

No 184

No 187

No 189

No 196

No 197

No 203

No 212

No 230

No 237

No 250

No 253

No 260

No 283

No 298

No 318

No 319

No 326

No 328

No 333

No 335

No 348

No 352

No 371

No 378

Vojin Plavsic: Interleaved Processing of Non-Numerical Data Stored on a Cyclic Memory. (Available at: FOA, Box 1165, S-581 11 Linköping, Sweden. FOA Report B30062E)

Arne Jönsson, Mikael Patel: An Interactive Flowcharting Technique for Communicating and Realizing Algorithms, 1984.

Johnny Eckerland: Retargeting of an Incremental Code Generator, 1984.

Henrik Nordin: On the Use of Typical Cases for Knowledge-Based Consultation and Teaching, 1985.

Zebo Peng: Steps Towards the Formalization of Designing VLSI Systems, 1985.

Johan Fagerström: Simulation and Evaluation of Architecture based on Asynchronous Processes, 1985.

Jalal Maleki: ICONStraint, A Dependency Directed Constraint Maintenance System, 1987.

Tony Larsson: On the Specification and Verification of VLSI Systems, 1986.

Ola Strömfors: A Structure Editor for Documents and Programs, 1986.

Christos Levcopoulos: New Results about the Approximation Behavior of the Greedy Triangulation, 1986.

Shamsul I. Chowdhury: Statistical Expert Systems - a Special Application Area for Knowledge-Based Computer Methodology, 1987.

Rober Bilos: Incremental Scanning and Token-Based Editing, 1987.

Hans Block: SPORT-SORT Sorting Algorithms and Sport Tournaments, 1987.

Ralph Rönnquist: Network and Lattice Based Approaches to the Representation of Knowledge, 1987.

Mariam Kamkar, Nahid Shahmehri: Affect-Chaining in Program Flow Analysis Applied to Queries of Programs, 1987.

Dan Strömberg: Transfer and Distribution of Application Programs, 1987.

Kristian Sandahl: Case Studies in Knowledge Acquisition, Migration and User Acceptance of Expert Systems, 1987.

Christer Bäckström: Reasoning about Interdependent Actions, 1988.

Mats Wirén: On Control Strategies and Incrementality in Unification-Based Chart Parsing, 1988.

Johan Hultman: A Software System for Defining and Controlling Actions in a Mechanical System, 1988.

Tim Hansen: Diagnosing Faults using Knowledge about Malfunctioning Behavior, 1988.

Jonas Löwgren: Supporting Design and Management of Expert System User Interfaces, 1989.

Ola Petersson: On Adaptive Sorting in Sequential and Parallel Models, 1989.

Yngve Larsson: Dynamic Configuration in a Distributed Environment, 1989.

Peter Åberg: Design of a Multiple View Presentation and Interaction Manager, 1989.

Henrik Eriksson: A Study in Domain-Oriented Tool Support for Knowledge Acquisition, 1989.

Ivan Rankin: The Deep Generation of Text in Expert Critiquing Systems, 1989.

Simin Nadjm-Tehrani: Contributions to the Declarative Approach to Debugging Prolog Programs, 1989.

Magnus Merkel: Temporal Information in Natural Language, 1989.

Ulf Nilsson: A Systematic Approach to Abstract Interpretation of Logic Programs, 1989.

Staffan Bonnier: Horn Clause Logic with External Procedures: Towards a Theoretical Framework, 1989.

Christer Hansson: A Prototype System for Logical Reasoning about Time and Action, 1990.

Björn Fjellborg: An Approach to Extraction of Pipeline Structures for VLSI High-Level Synthesis, 1990.

Patrick Doherty: A Three-Valued Approach to Non-Monotonic Reasoning, 1990.

Tomas Sokolnicki: Coaching Partial Plans: An Approach to Knowledge-Based Tutoring, 1990.

Lars Strömberg: Postmortem Debugging of Distributed Systems, 1990.

Torbjörn Näslund: SLDFA-Resolution - Computing Answers for Negative Queries, 1990.

Peter D. Holmes: Using Connectivity Graphs to Support Map-Related Reasoning, 1991.

Olof Johansson: Improving Implementation of Graphical User Interfaces for Object-Oriented Knowledge- Bases, 1991.

Rolf G Larsson: Aktivitetsbaserad kalkylering i ett nytt ekonomisystem, 1991.

Lena Srömbäck: Studies in Extended Unification-Based Formalism for Linguistic Description: An Algorithm for Feature Structures with Disjunction and a Proposal for Flexible Systems, 1992.

Mikael Pettersson: DML-A Language and System for the Generation of Efficient Compilers from Denotational Specification, 1992.

Andreas Kågedal: Logic Programming with External Procedures: an Implementation, 1992.

Patrick Lambrix: Aspects of Version Management of Composite Objects, 1992.

Xinli Gu: Testability Analysis and Improvement in High-Level Synthesis Systems, 1992.

Torbjörn Näslund: On the Role of Evaluations in Iterative Development of Managerial Support Systems, 1992.

Ulf Cederling: Industrial Software Development - a Case Study, 1992.

Magnus Morin: Predictable Cyclic Computations in Autonomous Systems: A Computational Model and Implementation, 1992.

Mehran Noghabai: Evaluation of Strategic Investments in Information Technology, 1993.

Mats Larsson: A Transformational Approach to Formal Digital System Design, 1993. 
Johan Ringström: Compiler Generation for Parallel Languages from Denotational Specifications, 1993. Michael Jansson: Propagation of Change in an Intelligent Information System, 1993. Jonni Harrius: An Architecture and a Knowledge Representation Model for Expert Critiquing Systems, 1993. Per Österling: Symbolic Modelling of the Dynamic Environments of Autonomous Agents, 1993. Johan Boye: Dependency-based Groudness Analysis of Functional Logic Programs, 1993. Lars Degerstedt: Tabulated Resolution for Well Founded Semantics, 1993.

Anna Moberg: Satellitkontor - en studie av kommunikationsmönster vid arbete på distans, 1993.

Peter Carlsson: Separation av företagsledning och finansiering - fallstudier av företagsledarutköp ur ett agentteoretiskt perspektiv, 1994.

Camilla Sjöström: Revision och lagreglering - ett historiskt perspektiv, 1994.

Cecilia Sjöberg: Voices in Design: Argumentation in Participatory Development, 1994.

Lars Viklund: Contributions to a High-level Programming Environment for a Scientific Computing, 1994.

Peter Loborg: Error Recovery Support in Manufacturing Control Systems, 1994.

Owen Eriksson: Informationssystem med verksamhetskvalitet - utvärdering baserat på ett verksamhetsinriktat och samskapande perspektiv, 1994.

Karin Pettersson: Informationssystemstrukturering, ansvarsfördelning och användarinflytande - En komparativ studie med utgångspunkt i två informationssystemstrategier, 1994.

Lars Poignant: Informationsteknologi och företagsetablering - Effekter på produktivitet och region, 1994.

Gustav Fahl: Object Views of Relational Data in Multidatabase Systems, 1994.

Henrik Nilsson: A Declarative Approach to Debugging for Lazy Functional Languages, 1994.

Jonas Lind: Creditor - Firm Relations: an Interdisciplinary Analysis, 1994.

Martin Sköld: Active Rules based on Object Relational Queries - Efficient Change Monitoring Techniques, 1994.

Pär Carlshamre: A Collaborative Approach to Usability Engineering: Technical Communicators and System Developers in Usability-Oriented Systems Development, 1994.

Stefan Cronholm: Varför CASE-verktyg i systemutveckling? - En motiv- och konsekvensstudie avseende arbetssätt och arbetsformer, 1994.

Mikael Lindvall: A Study of Traceability in Object-Oriented Systems Development, 1994.

Fredrik Nilsson: Strategi och ekonomisk styrning - En studie av Sandviks förvärv av Bahco Verktyg, 1994.

Hans Olsén: Collage Induction: Proving Properties of Logic Programs by Program Synthesis, 1994.

Lars Karlsson: Specification and Synthesis of Plans Using the Features and Fluents Framework, 1995.

Ulf Söderman: On Conceptual Modelling of Mode Switching Systems, 1995.

Choong-ho Yi: Reasoning about Concurrent Actions in the Trajectory Semantics, 1995.

Bo Lagerström: Successiv resultatavräkning av pågående arbeten. - Fallstudier i tre byggföretag, 1995.

Peter Jonsson: Complexity of State-Variable Planning under Structural Restrictions, 1995.

Anders Avdic: Arbetsintegrerad systemutveckling med kalkylprogram, 1995.

Eva L Ragnemalm: Towards Student Modelling through Collaborative Dialogue with a Learning Companion, 1995.

Eva Toller: Contributions to Parallel Multiparadigm Languages: Combining Object-Oriented and Rule-Based Programming, 1995.

Erik Stoy: A Petri Net Based Unified Representation for Hardware/Software Co-Design, 1995.

Johan Herber: Environment Support for Building Structured Mathematical Models, 1995.

Stefan Svenberg: Structure-Driven Derivation of Inter-Lingual Functor-Argument Trees for Multi-Lingual Generation, 1995.

Hee-Cheol Kim: Prediction and Postdiction under Uncertainty, 1995.

Dan Fristedt: Metoder i användning - mot förbättring av systemutveckling genom situationell metodkunskap och metodanalys, 1995.

Malin Bergvall: Systemförvaltning i praktiken - en kvalitativ studie avseende centrala begrepp, aktiviteter och ansvarsroller, 1995.

Joachim Karlsson: Towards a Strategy for Software Requirements Selection, 1995.

Jakob Axelsson: Schedulability-Driven Partitioning of Heterogeneous Real-Time Systems, 1995.

Göran Forslund: Toward Cooperative Advice-Giving Systems: The Expert Systems Experience, 1995.

Jörgen Andersson: Bilder av småföretagares ekonomistyrning, 1995.

Staffan Flodin: Efficient Management of Object-Oriented Queries with Late Binding, 1996.

Vadim Engelson: An Approach to Automatic Construction of Graphical User Interfaces for Applications in Scientific Computing, 1996.

Magnus Werner : Multidatabase Integration using Polymorphic Queries and Views, 1996.

Mikael Lind: Affärsprocessinriktad förändringsanalys - utveckling och tillämpning av synsätt och metod, 1996.

Jonas Hallberg: High-Level Synthesis under Local Timing Constraints, 1996.

Kristina Larsen: Förutsättningar och begränsningar för arbete på distans - erfarenheter från fyra svenska företag. 1996.

Mikael Johansson: Quality Functions for Requirements Engineering Methods, 1996.

Patrik Nordling: The Simulation of Rolling Bearing Dynamics on Parallel Computers, 1996.

Anders Ekman: Exploration of Polygonal Environments, 1996.

Niclas Andersson: Compilation of Mathematical Models to Parallel Code, 1996. 
Johan Jenvald: Simulation and Data Collection in Battle Training, 1996.

Niclas OhIsson: Software Quality Engineering by Early Identification of Fault-Prone Modules, 1996.

Mikael Ericsson: Commenting Systems as Design Support-A Wizard-of-Oz Study, 1996.

Jörgen Lindström: Chefers användning av kommunikationsteknik, 1996.

Esa Falkenroth: Data Management in Control Applications - A Proposal Based on Active Database Systems, 1996.

Niclas Wahllöf: A Default Extension to Description Logics and its Applications, 1996.

Annika Larsson: Ekonomisk Styrning och Organisatorisk Passion - ett interaktivt perspektiv, 1997.

Ling Lin: A Value-based Indexing Technique for Time Sequences, 1997.

Rego Granlund: $C^{3}$ Fire - A Microworld Supporting Emergency Management Training, 1997.

Peter Ingels: A Robust Text Processing Technique Applied to Lexical Error Recovery, 1997.

Per-Arne Persson: Toward a Grounded Theory for Support of Command and Control in Military Coalitions, 1997. Jonas S Karlsson: A Scalable Data Structure for a Parallel Data Server, 1997.

Carita Åbom: Videomötesteknik i olika affärssituationer - möjligheter och hinder, 1997.

Tommy Wedlund: Att skapa en företagsanpassad systemutvecklingsmodell - genom rekonstruktion, värdering och vidareutveckling i T50-bolag inom ABB, 1997.

Silvia Coradeschi: A Decision-Mechanism for Reactive and Coordinated Agents, 1997.

Jan Ollinen: Det flexibla kontorets utveckling på Digital - Ett stöd för multiflex? 1997.

David Byers: Towards Estimating Software Testability Using Static Analysis, 1997.

Fredrik Eklund: Declarative Error Diagnosis of GAPLog Programs, 1997.

Gunilla Ivefors: Krigsspel och Informationsteknik inför en oförutsägbar framtid, 1997.

Jens-Olof Lindh: Analysing Traffic Safety from a Case-Based Reasoning Perspective, 1997

Jukka Mäki-Turja:. Smalltalk - a suitable Real-Time Language, 1997.

Juha Takkinen: CAFE: Towards a Conceptual Model for Information Management in Electronic Mail, 1997.

Man Lin: Formal Analysis of Reactive Rule-based Programs, 1997.

Mats Gustafsson: Bringing Role-Based Access Control to Distributed Systems, 1997.

Boris Karlsson: Metodanalys för förståelse och utveckling av systemutvecklingsverksamhet. Analys och värdering av systemutvecklingsmodeller och dess användning, 1997.

Marcus Bjäreland: Two Aspects of Automating Logics of Action and Change - Regression and Tractability, 1998.

Jan Håkegård: Hierarchical Test Architecture and Board-Level Test Controller Synthesis, 1998.

Per-Ove Zetterlund: Normering av svensk redovisning - En studie av tillkomsten av Redovisningsrådets rekommendation om koncernredovisning (RR01:91), 1998.

Jimmy Tjäder: Projektledaren \& planen - en studie av projektledning i tre installations- och systemutvecklingsprojekt, 1998.

Ulf Melin: Informationssystem vid ökad affärs- och processorientering - egenskaper, strategier och utveckling, 1998.

Tim Heyer: COMPASS: Introduction of Formal Methods in Code Development and Inspection, 1998.

Patrik Hägglund: Programming Languages for Computer Algebra, 1998.

Marie-Therese Christiansson: Inter-organisatorisk verksamhetsutveckling - metoder som stöd vid utveckling av partnerskap och informationssystem, 1998.

Christina Wennestam: Information om immateriella resurser. Investeringar i forskning och utveckling samt i personal inom skogsindustrin, 1998.

Joakim Gustafsson: Extending Temporal Action Logic for Ramification and Concurrency, 1998.

Henrik André-Jönsson: Indexing time-series data using text indexing methods, 1999.

Erik Larsson: High-Level Testability Analysis and Enhancement Techniques, 1998.

Carl-Johan Westin: Informationsförsörjning: en fråga om ansvar - aktiviteter och uppdrag i fem stora svenska organisationers operativa informationsförsörjning, 1998.

Åse Jansson: Miljöhänsyn - en del i företags styrning, 1998.

Thomas Padron-McCarthy: Performance-Polymorphic Declarative Queries, 1998.

Anders Bäckström: Värdeskapande kreditgivning - Kreditriskhantering ur ett agentteoretiskt perspektiv, 1998.

Ulf Seigerroth: Integration av förändringsmetoder - en modell för välgrundad metodintegration, 1999.

Fredrik Öberg: Object-Oriented Frameworks - A New Strategy for Case Tool Development, 1998.

Jonas Mellin: Predictable Event Monitoring, 1998.

Joakim Eriksson: Specifying and Managing Rules in an Active Real-Time Database System, 1998.

Bengt E W Andersson: Samverkande informationssystem mellan aktörer i offentliga åtaganden - En teori om aktörsarenor i samverkan om utbyte av information, 1998.

Pawel Pietrzak: Static Incorrectness Diagnosis of CLP (FD), 1999.

Tobias Ritzau: Real-Time Reference Counting in RT-Java, 1999.

Anders Ferntoft: Elektronisk affärskommunikation - kontaktkostnader och kontaktprocesser mellan kunder och leverantörer på producentmarknader, 1999.

Jo Skåmedal: Arbete på distans och arbetsformens påverkan på resor och resmönster, 1999.

Johan Alvehus: Mötets metaforer. En studie av berättelser om möten, 1999. 
Magnus Lindahl: Bankens villkor i låneavtal vid kreditgivning till högt belånade företagsförvärv: En studie ur ett agentteoretiskt perspektiv, 2000.

Martin V. Howard: Designing dynamic visualizations of temporal data, 1999.

Jesper Andersson: Towards Reactive Software Architectures, 1999.

Anders Henriksson: Unique kernel diagnosis, 1999.

Pär J. Ågerfalk: Pragmatization of Information Systems - A Theoretical and Methodological Outline, 1999. Charlotte Björkegren: Learning for the next project - Bearers and barriers in knowledge transfer within an organisation, 1999.

Håkan Nilsson: Informationsteknik som drivkraft i granskningsprocessen - En studie av fyra revisionsbyråer, 2000.

Erik Berglund: Use-Oriented Documentation in Software Development, 1999.

Klas Gäre: Verksamhetsförändringar i samband med IS-införande, 1999.

Anders Subotic: Software Quality Inspection, 1999.

Svein Bergum: Managerial communication in telework, 2000.

Flavius Gruian: Energy-Aware Design of Digital Systems, 2000.

Karin Hedström: Kunskapsanvändning och kunskapsutveckling hos verksamhetskonsulter - Erfarenheter från ett FOU-samarbete, 2000.

Linda Askenäs: Affärssystemet - En studie om teknikens aktiva och passiva roll i en organisation, 2000.

Jean Paul Meynard: Control of industrial robots through high-level task programming, 2000.

Lars Hult: Publika Gränsytor - ett designexempel, 2000.

Paul Pop: Scheduling and Communication Synthesis for Distributed Real-Time Systems, 2000.

Göran Hultgren: Nätverksinriktad Förändringsanalys - perspektiv och metoder som stöd för förståelse och utveckling av affärsrelationer och informationssystem, 2000.

Magnus Kald: The role of management control systems in strategic business units, 2000.

Mikael Cäker: Vad kostar kunden? Modeller för intern redovisning, 2000.

Ewa Braf: Organisationers kunskapsverksamheter - en kritisk studie av "knowledge management", 2000.

Henrik Lindberg: Webbaserade affärsprocesser - Möjligheter och begränsningar, 2000.

Benneth Christiansson: Att komponentbasera informationssystem - Vad säger teori och praktik?, 2000.

Ola Pettersson: Deliberation in a Mobile Robot, 2000.

Dan Lawesson: Towards Behavioral Model Fault Isolation for Object Oriented Control Systems, 2000.

Johan Moe: Execution Tracing of Large Distributed Systems, 2001.

Yuxiao Zhao: XML-based Frameworks for Internet Commerce and an Implementation of B2B e-procurement, 2001.

Annika Flycht-Eriksson: Domain Knowledge Management in Information-providing Dialogue systems, 2001

Per-Arne Segerkvist: Webbaserade imaginära organisationers samverkansformer: Informationssystemarkitektur och aktörssamverkan som förutsättningar för affärsprocesser, 2001.

Stefan Svarén: Styrning av investeringar i divisionaliserade företag - Ett koncernperspektiv, 2001.

Lin Han: Secure and Scalable E-Service Software Delivery, 2001.

Emma Hansson: Optionsprogram för anställda - en studie av svenska börsföretag, 2001.

Susanne Odar: IT som stöd för strategiska beslut, en studie av datorimplementerade modeller av verksamhet som stöd för beslut om anskaffning av JAS 1982, 2002.

Stefan Holgersson: IT-system och filtrering av verksamhetskunskap - kvalitetsproblem vid analyser och beslutsfattande som bygger på uppgifter hämtade från polisens IT-system, 2001.

Per Oscarsson: Informationssäkerhet i verksamheter - begrepp och modeller som stöd för förståelse av informationssäkerhet och dess hantering, 2001.

Luis Alejandro Cortes: A Petri Net Based Modeling and Verification Technique for Real-Time Embedded Systems, 2001.

Niklas Sandell: Redovisning i skuggan av en bankkris - Värdering av fastigheter. 2001

Fredrik Elg: Ett dynamiskt perspektiv på individuella skillnader av heuristisk kompetens, intelligens, mentala modeller, mål och konfidens i kontroll av mikrovärlden Moro, 2002.

Peter Aronsson: Automatic Parallelization of Simulation Code from Equation Based Simulation Languages, 2002. Bourhane Kadmiry: Fuzzy Control of Unmanned Helicopter, 2002.

Patrik Haslum: Prediction as a Knowledge Representation Problem: A Case Study in Model Design, 2002.

Robert Sevenius: On the instruments of governance - A law \& economics study of capital instruments in limited liability companies, 2002.

Johan Petersson: Lokala elektroniska marknadsplatser - informationssystem för platsbundna affärer, 2002.

Peter Bunus: Debugging and Structural Analysis of Declarative Equation-Based Languages, 2002.

Gert Jervan: High-Level Test Generation and Built-In Self-Test Techniques for Digital Systems, 2002.

Fredrika Berglund: Management Control and Strategy - a Case Study of Pharmaceutical Drug Development, 2002.

Fredrik Karlsson: Meta-Method for Method Configuration - A Rational Unified Process Case, 2002.

Sorin Manolache: Schedulability Analysis of Real-Time Systems with Stochastic Task Execution Times, 2002.

Diana Szentiványi: Performance and Availability Trade-offs in Fault-Tolerant Middleware, 2002.

Iakov Nakhimovski: Modeling and Simulation of Contacting Flexible Bodies in Multibody Systems, 2002.

Levon Saldamli: PDEModelica - Towards a High-Level Language for Modeling with Partial Differential Equations, 2002.

Almut Herzog: Secure Execution Environment for Java Electronic Services, 2002. 
No 1130

Jon Edvardsson: Contributions to Program- and Specification-based Test Data Generation, 2002.

Anders Arpteg: Adaptive Semi-structured Information Extraction, 2002.

Andrzej Bednarski: A Dynamic Programming Approach to Optimal Retargetable Code Generation for Irregular Architectures, 2002.

Mattias Arvola: Good to use! : Use quality of multi-user applications in the home, 2003.

Lennart Ljung: Utveckling av en projektivitetsmodell - om organisationers förmåga att tillämpa projektarbetsformen, 2003.

Pernilla Qvarfordt: User experience of spoken feedback in multimodal interaction, 2003.

Alexander Siemers: Visualization of Dynamic Multibody Simulation With Special Reference to Contacts, 2003.

Jens Gustavsson: Towards Unanticipated Runtime Software Evolution, 2003.

Calin Curescu: Adaptive QoS-aware Resource Allocation for Wireless Networks, 2003.

Anna Andersson: Management Information Systems in Process-oriented Healthcare Organisations, 2003.

Björn Johansson: Feedforward Control in Dynamic Situations, 2003.

Traian Pop: Scheduling and Optimisation of Heterogeneous Time/Event-Triggered Distributed Embedded Systems, 2003.

Britt-Marie Johansson: Kundkommunikation på distans - en studie om kommunikationsmediets betydelse i affärstransaktioner, 2003.

Aleksandra Tešanovic: Towards Aspectual Component-Based Real-Time System Development, 2003.

Arja Vainio-Larsson: Designing for Use in a Future Context - Five Case Studies in Retrospect, 2003.

Peter Nilsson: Svenska bankers redovisningsval vid reservering för befarade kreditförluster - En studie vid införandet av nya redovisningsregler, 2003.

Fredrik Ericsson: Information Technology for Learning and Acquiring of Work Knowledge, 2003. Marcus Comstedt: Towards Fine-Grained Binary Composition through Link Time Weaving, 2003.

Åsa Hedenskog: Increasing the Automation of Radio Network Control, 2003.

Claudiu Duma: Security and Efficiency Tradeoffs in Multicast Group Key Management, 2003.

Emma Eliason: Effektanalys av IT-systems handlingsutrymme, 2003.

Carl Cederberg: Experiments in Indirect Fault Injection with Open Source and Industrial Software, 2003.

Daniel Karlsson: Towards Formal Verification in a Component-based Reuse Methodology, 2003.

Anders Hjalmarsson: Att etablera och vidmakthålla förbättringsverksamhet - behovet av koordination och interaktion vid förändring av systemutvecklingsverksamheter, 2004.

Pontus Johansson: Design and Development of Recommender Dialogue Systems, 2004.

Charlotte Stoltz: Calling for Call Centres - A Study of Call Centre Locations in a Swedish Rural Region, 2004.

Björn Johansson: Deciding on Using Application Service Provision in SMEs, 2004.

Genevieve Gorrell: Language Modelling and Error Handling in Spoken Dialogue Systems, 2004.

Ulf Johansson: Rule Extraction - the Key to Accurate and Comprehensible Data Mining Models, 2004.

Sonia Sangari: Computational Models of Some Communicative Head Movements, 2004

Hans Nässla: Intra-Family Information Flow and Prospects for Communication Systems, 2004.

Henrik Sällberg: On the value of customer loyalty programs - A study of point programs and switching costs, 2004.

Ulf Larsson: Designarbete i dialog - karaktärisering av interaktionen mellan användare och utvecklare i en systemutvecklingsprocess, 2004.

Andreas Borg: Contribution to Management and Validation of Non-Functional Requirements, 2004.

Per-Ola Kristensson: Large Vocabulary Shorthand Writing on Stylus Keyboard, 2004.

Pär-Anders Albinsson: Interacting with Command and Control Systems: Tools for Operators and Designers, 2004.

Ioan Chisalita: Safety-Oriented Communication in Mobile Networks for Vehicles, 2004.

Thomas Gustafsson: Maintaining Data Consistency in Embedded Databases for Vehicular Systems, 2004.

Vaida Jakoniené: A Study in Integrating Multiple Biological Data Sources, 2005.

Abdil Rashid Mohamed: High-Level Techniques for Built-In Self-Test Resources Optimization, 2005.

Adrian Pop: Contributions to Meta-Modeling Tools and Methods, 2005.

Fidel Vascós Palacios: On the information exchange between physicians and social insurance officers in the sick leave process: an Activity Theoretical perspective, 2005.

Jenny Lagsten: Verksamhetsutvecklande utvärdering i informationssystemprojekt, 2005.

Emma Larsdotter Nilsson: Modeling, Simulation, and Visualization of Metabolic Pathways Using Modelica, 2005.

Christina Keller: Virtual Learning Environments in higher education. A study of students' acceptance of educational technology, 2005.

Cécile Åberg: Integration of organizational workflows and the Semantic Web, 2005.

Anders Forsman: Standardisering som grund för informationssamverkan och IT-tjänster - En fallstudie baserad på trafikinformationstjänsten RDS-TMC, 2005.

Yu-Hsing Huang: A systemic traffic accident model, 2005.

Jan Olausson: Att modellera uppdrag - grunder för förståelse av processinriktade informationssystem i transaktionsintensiva verksamheter, 2005.

Petter Ahlström: Affärsstrategier för seniorbostadsmarknaden, 2005.

Mathias Cöster: Beyond IT and Productivity - How Digitization Transformed the Graphic Industry, 2005.

Åsa Horzella: Beyond IT and Productivity - Effects of Digitized Information Flows in Grocery Distribution, 2005.

Maria Kollberg: Beyond IT and Productivity - Effects of Digitized Information Flows in the Logging Industry, 2005.

David Dinka: Role and Identity - Experience of technology in professional settings, 2005. 
Andreas Hansson: Increasing the Storage Capacity of Recursive Auto-associative Memory by Segmenting Data, 2005.

No 1192

No 1194

No 1204

No 1206

No 1207

No 1209

No 1225

No 1228

No 1229

No 1231

No 1233

No 1244

No 1248

No 1263

FiF-a 90

No 1272

No 1277

No 1283

FiF-a 91

No 1286

No 1293

No 1302

No 1303

No 1305

No 1306

No 1307

No 1309

No 1312

No 1313

No 1317

No 1320

No 1323

No 1329

No 1331

No 1332

No 1333

No 1337

No 1339

No 1351

No 1353

No 1356

No 1359

No 1361

No 1363

No 1371

No 1373

No 1381

No 1386

No 1387

No 1392

No 1393

No 1401

No 1410

No 1421

No 1427

No 1450

No 1459

No 1466

Nicklas Bergfeldt: Towards Detached Communication for Robot Cooperation, 2005.

Dennis Maciuszek: Towards Dependable Virtual Companions for Later Life, 2005.

Beatrice Alenljung: Decision-making in the Requirements Engineering Process: A Human-centered Approach, 2005.

Anders Larsson: System-on-Chip Test Scheduling and Test Infrastructure Design, 2005

John Wilander: Policy and Implementation Assurance for Software Security, 2005.

Andreas Käll: Översättningar av en managementmodell - En studie av införandet av Balanced Scorecard i ett landsting, 2005.

He Tan: Aligning and Merging Biomedical Ontologies, 2006.

Artur Wilk: Descriptive Types for XML Query Language Xcerpt, 2006.

Per Olof Pettersson: Sampling-based Path Planning for an Autonomous Helicopter, 2006.

Kalle Burbeck: Adaptive Real-time Anomaly Detection for Safeguarding Critical Networks, 2006.

Daniela Mihailescu: Implementation Methodology in Action: A Study of an Enterprise Systems Implementation Methodology, 2006.

Jörgen Skågeby: Public and Non-public gifting on the Internet, 2006.

Karolina Eliasson: The Use of Case-Based Reasoning in a Human-Robot Dialog System, 2006.

Misook Park-Westman: Managing Competence Development Programs in a Cross-Cultural Organisation - What are the Barriers and Enablers, 2006.

Amra Halilovic: Ett praktikperspektiv på hantering av mjukvarukomponenter, 2006.

Raquel Flodström: A Framework for the Strategic Management of Information Technology, 2006.

Viacheslav Izosimov: Scheduling and Optimization of Fault-Tolerant Embedded Systems, 2006.

Håkan Hasewinkel: A Blueprint for Using Commercial Games off the Shelf in Defence Training, Education and Research Simulations, 2006.

Hanna Broberg: Verksamhetsanpassade IT-stöd - Designteori och metod, 2006.

Robert Kaminski: Towards an XML Document Restructuring Framework, 2006.

Jiri Trnka: Prerequisites for data sharing in emergency management, 2007.

Björn Hägglund: A Framework for Designing Constraint Stores, 2007.

Daniel Andreasson: Slack-Time Aware Dynamic Routing Schemes for On-Chip Networks, 2007.

Magnus Ingmarsson: Modelling User Tasks and Intentions for Service Discovery in Ubiquitous Computing, 2007.

Gustaf Svedjemo: Ontology as Conceptual Schema when Modelling Historical Maps for Database Storage, 2007.

Gianpaolo Conte: Navigation Functionalities for an Autonomous UAV Helicopter, 2007.

Ola Leifler: User-Centric Critiquing in Command and Control: The DKExpert and ComPlan Approaches, 2007.

Henrik Svensson: Embodied simulation as off-line representation, 2007.

Zhiyuan He: System-on-Chip Test Scheduling with Defect-Probability and Temperature Considerations, 2007.

Jonas EImqvist: Components, Safety Interfaces and Compositional Analysis, 2007

Håkan Sundblad: Question Classification in Question Answering Systems, 2007.

Magnus Lundqvist: Information Demand and Use: Improving Information Flow within Small-scale Business Contexts, 2007.

Martin Magnusson: Deductive Planning and Composite Actions in Temporal Action Logic, 2007.

Mikael Asplund: Restoring Consistency after Network Partitions, 2007.

Martin Fransson: Towards Individualized Drug Dosage - General Methods and Case Studies, 2007.

Karin Camara: A Visual Query Language Served by a Multi-sensor Environment, 2007.

David Broman: Safety, Security, and Semantic Aspects of Equation-Based Object-Oriented Languages and Environments, 2007.

Mikhail Chalabine: Invasive Interactive Parallelization, 2007.

Susanna Nilsson: A Holistic Approach to Usability Evaluations of Mixed Reality Systems, 2008.

Shanai Ardi: A Model and Implementation of a Security Plug-in for the Software Life Cycle, 2008.

Erik Kuiper: Mobility and Routing in a Delay-tolerant Network of Unmanned Aerial Vehicles, 2008.

Jana Rambusch: Situated Play, 2008.

Martin Karresand: Completing the Picture - Fragments and Back Again, 2008.

Per Nyblom: Dynamic Abstraction for Interleaved Task Planning and Execution, 2008.

Fredrik Lantz: Terrain Object Recognition and Context Fusion for Decision Support, 2008.

Martin Östlund: Assistance Plus: 3D-mediated Advice-giving on Pharmaceutical Products, 2008.

Håkan Lundvall: Automatic Parallelization using Pipelining for Equation-Based Simulation Languages, 2008.

Mirko Thorstensson: Using Observers for Model Based Data Collection in Distributed Tactical Operations, 2008.

Bahlol Rahimi: Implementation of Health Information Systems, 2008.

Maria Holmqvist: Word Alignment by Re-using Parallel Phrases, 2008.

Mattias Eriksson: Integrated Software Pipelining, 2009.

Annika Öhgren: Towards an Ontology Development Methodology for Small and Medium-sized Enterprises, 2009.

Rickard Holsmark: Deadlock Free Routing in Mesh Networks on Chip with Regions, 2009.

Sara Stymne: Compound Processing for Phrase-Based Statistical Machine Translation, 2009.

Tommy Ellqvist: Supporting Scientific Collaboration through Workflows and Provenance, 2009.

Fabian Segelström: Visualisations in Service Design, 2010.

Min Bao: System Level Techniques for Temperature-Aware Energy Optimization, 2010.

Mohammad Saifullah: Exploring Biologically Inspired Interactive Networks for Object Recognition, 2011 
No 1558

No 1582

No 1586

No 1588

No 1589

No 1592

No 1606

No 1624

No 1627

No 1644

No 1647

No 1657

No 1683

No 1688

No 1715

No 1716

No 1722

No 1732

FiF 118

No 1758

No 1771

No 1777

No 1780

No 1782

No 1783

No 1827

No 1836

No 1848

No 1871

No 1881

No 1886

No 1892
Qiang Liu: Dealing with Missing Mappings and Structure in a Network of Ontologies, 2011.

Ruxandra Pop: Mapping Concurrent Applications to Multiprocessor Systems with Multithreaded Processors and Network on Chip-Based Interconnections, 2011.

Per-Magnus Olsson: Positioning Algorithms for Surveillance Using Unmanned Aerial Vehicles, 2011.

Anna Vapen: Contributions to Web Authentication for Untrusted Computers, 2011.

Loove Broms: Sustainable Interactions: Studies in the Design of Energy Awareness Artefacts, 2011.

Johan Blomkvist: Conceptualising Prototypes in Service Design, 2011.

Håkan Warnquist: Computer-Assisted Troubleshooting for Efficient Off-board Diagnosis, 2011.

Jakob Rosén: Predictable Real-Time Applications on Multiprocessor Systems-on-Chip, 2011.

Usman Dastgeer: Skeleton Programming for Heterogeneous GPU-based Systems, 2011.

David Landén: Complex Task Allocation for Delegation: From Theory to Practice, 2011.

Kristian Stavåker: Contributions to Parallel Simulation of Equation-Based Models on

Graphics Processing Units, 2011.

Mariusz Wzorek: Selected Aspects of Navigation and Path Planning in Unmanned Aircraft Systems, 2011.

Piotr Rudol: Increasing Autonomy of Unmanned Aircraft Systems Through the Use of Imaging Sensors, 2011.

Anders Carstensen: The Evolution of the Connector View Concept: Enterprise Models for Interoperability

Solutions in the Extended Enterprise, 2011.

Jody Foo: Computational Terminology: Exploring Bilingual and Monolingual Term Extraction, 2012.

Anders Fröberg: Models and Tools for Distributed User Interface Development, 2012.

Dimitar Nikolov: Optimizing Fault Tolerance for Real-Time Systems, 2012.

Dennis Andersson: Mission Experience: How to Model and Capture it to Enable Vicarious Learning, 2013.

Massimiliano Raciti: Anomaly Detection and its Adaptation: Studies on Cyber-physical Systems, 2013.

Banafsheh Khademhosseinieh: Towards an Approach for Efficiency Evaluation of

Enterprise Modeling Methods, 2013.

Amy Rankin: Resilience in High Risk Work: Analysing Adaptive Performance, 2013.

Martin Sjölund: Tools for Understanding, Debugging, and Simulation Performance Improvement of EquationBased Models, 2013.

Karl Hammar: Towards an Ontology Design Pattern Quality Model, 2013.

Maria Vasilevskaya: Designing Security-enhanced Embedded Systems: Bridging Two Islands of Expertise, 2013. Ekhiotz Vergara: Exploiting Energy Awareness in Mobile Communication, 2013.

Valentina Ivanova: Integration of Ontology Alignment and Ontology Debugging for Taxonomy Networks, 2014.

Dag Sonntag: A Study of Chain Graph Interpretations, 2014.

Kiril Kiryazov: Grounding Emotion Appraisal in Autonomous Humanoids, 2014.

Zlatan Dragisic: Completing the Is-a Structure in Description Logics Ontologies, 2014.

Erik Hansson: Code Generation and Global Optimization Techniques for a Reconfigurable PRAM-NUMA Multicore Architecture, 2014.

Nicolas Melot: Energy-Efficient Computing over Streams with Massively Parallel Architectures, 2015.

Mahder Gebremedhin: Automatic and Explicit Parallelization Approaches for Mathematical Simulation Models, 2015.

Mikael Nilsson: Efficient Temporal Reasoning with Uncertainty, 2015.

Vladislavs Jahundovics: Automatic Verification of Parameterized Sytems by Over-Approximation, 2015.

Camilla Kirkegaard: Adding Challenge to a Teachable Agent in a Virtual Learning Environment, 2016.

Vengatanathan Krishnamoorthi: Efficient and Scalable Content Delivery of Linear and Interactive Branched Videos, 2016.

Andreas Löfwenmark: Timing Predictability in Future Multi-Core Avionics Systems, 2017.

Anders Andersson: Extensions for Distributed Moving Base Driving Simulators, 2017.

Olov Andersson: Methods for Scalable and Safe Robot Learning, 2017.

Robin Keskisärkkä: Towards Semantically Enabled Complex Event Processing, 2017.

Daniel de Leng: Spatio-Temporal Stream Reasoning with Adaptive State Stream Generation, 2017.

Johan Falkenjack: Towards a Model of General Text Complexity for Swedish, 2018.

Magdalena Granåsen: Exploring $\mathrm{C} 2$ Capability and Effectiveness in Challenging Environments: Interorganizational Crisis Management, Military Operations and Cyber Defence, 2019.

Alachew Mengist: Methods and Tools for Efficient Model-Based Development of Cyber-Physical Systems with Emphasis on Model and Tool Integration, 2019.

Klervie Toczé: Latency-aware Resource Management at the Edge, 2020.

Chih-Yuan Lin: A Timing Approach to Network-based Anomaly Detection for SCADA Systems, 2020.

August Ernstsson: Designing a Modern Skeleton Programming Framework for Parallel and Heterogeneous Systems, 2020.

John Törnblom: Formal Verification of Tree Ensembles in Safety-Critical Applications, 2020. 


\section{FACULTY OF SCIENCE AND ENGINEERING}

Linköping Studies in Science and Technology, Licentiate Thesis No. 1892, 2020 Department of Computer and Information Science

Linköping University

SE-581 83 Linköping, Sweden

wWw.liu.se 